\title{
Impact of cardiac anomalies in the prognosis of patients with velo-cardio-facial syndrome
}

\author{
Alexandra Maştaleru, Maria-Magdalena Leon-Constantin, \\ Irina Abdulan, Alexandra Jitaru, Eva Gavril, Mitu Florin
}

\begin{abstract}
Alexandra Maștaleru - Universitatea de Medicină şi Farmacie "Grigore T Popa" - Iasi, Romania, Facultatea de Medicină, Departamentul Medicale I, adresa: Strada Universităţii nr 16, Iasi, Romania; Spitalul Clinic de Recuperare - Clinica de Recuperare Cardiovasculară, Maria-Magdalena Leon-Constantin - Universitatea de Medicină și Farmacie "Grigore T Popa" Iasi, Romania, Facultatea de Medicină, Departamentul Medicale I, adresa: Strada Universităţii nr 16, Iasi, Romania; Spitalul Clinic de Recuperare - Clinica de Recuperare Cardiovasculară,

Irina Abdulan - Universitatea de Medicină și Farmacie "Grigore T Popa" - Iasi, Romania, Facultatea de Medicină, Departamentul Medicale I, adresa: Strada Universității nr 16, Iasi, Romania; Spitalul Clinic de Recuperare - Clinica de Recuperare Cardiovasculară,

Alexandra Jitaru - Universitatea de Medicină și Farmacie "Grigore T Popa" - Iasi, Romania, Facultatea de Medicină, Departamentul Medicale I, adresa: Strada Universității nr 16, Iasi, Romania; Spitalul Clinic de Recuperare - Clinica de Recuperare Cardiovasculară

Eva Gavril - Universitatea de Medicină și Farmacie "Grigore T Popa" - Iasi, Romania, Facultatea de Medicină, Departamentul Medicale I, adresa: Strada Universității nr 16, Iasi, Romania; Spitalul Clinic de Recuperare - Clinica de Recuperare Cardiovasculară

Florin Mitu - Universitatea de Medicină și Farmacie "Grigore T Popa" - Iasi, Romania, Facultatea de Medicină, Departamentul Medicale I, adresa: Strada Universității nr 16, Iasi, Romania; Spitalul Clinic de Recuperare - Șeful Clinicii de Recuperare Cardiovasculară
\end{abstract}

\section{ABSTRACT}

One of the most common multiple anomaly syndromes in human is the velo-cardio-facial syndrome (VCFS). A very important step in managing a patient with a $22 q 11.2$ deletion is to identify the exact phenotypic manifestations so that appropriate counseling and anticipatory care can be provided. Patients with VCFS have a 25 times higher rate of psychosis than general population. Therefore, it is almost certain that a genomic factor or factors in the deleted region influence brain development and/or function. Childhood psychiatric manifestations of VCFS include mood dysregulation, anxiety disorders, attention deficit hyperactivity disorder (ADHD) and autism spectrum disorders. VCFS is the most commonly 
r.m.\% known genetic risk factor for schizophrenia. The $25 \%$ risk of developing schizophrenia is a great concern of the patients and their families given its gravity and social stigma. Regarding the psychopharmacological treatment, the therapies need to be carefully chosen, taking into account literature data on tolerability and efficacy. Thus, it is particularly important to know the features and symptoms of the disease in order to a good evaluation and monitoring of the patient. A multidisciplinary approach is fundamental to ensure that the patient will be able to attain his or her maximal potential.

\section{KEYWORDS:}

Velo-cardio-facial syndrome, cardiac malformations, schizophrenia

\section{INTRODUCTION}

One of the most common multiple anomaly syndromes in human is the velo-cardio-facial syndrome (VCFS). Other names as DiGeorge sequence, 22q11 deletion syndrome, $\mathrm{CATCH}$ 22 , conotruncal anomalies face syndrome and Sedlačková syndrome have all been given to the same disorder (1,2). Approximately 6$10 \%$ of cases are familial, while most occur de novo. Nearly $75 \%$ of patients with a 22q11.2 deletion have a congenital heart malformation, as well as aortic arch anomalies (1).

VCFS syndrome has an extensive phenotype with more than 180 clinical features. It basically involves every organ and system. Early recognition of the deletion is important, so that the treatment of the involved organ anomalies can be initiated, screening for associated malformations performed and prevention of neuropsychological problems provided. A multidisciplinary approach is fundamental to ensure that the patient will be able to attain his or her maximal potential. Psychiatrists are an important part of the team that evaluate and treat these patients who frequently present a number of common psychiatric illnesses and phenotypic features including attention deficit disorder, schizophrenia or bipolar disorder. The psychiatric manifestations are highly variable, some individuals being essentially normal or at the mildest end of the spectrum, or some with most severe cases having life-threatening and life-impairing problems.

\section{MOLECULAR CHARACTERISTICS AND INHERITANCE PATTERN}

The 22q11.2 locus is flanked by chromosome specific, low copy repeats that share more than $97 \%$ sequence homology. This fact causes the region to be prone to misalignment of reduced copy repeats during meiosis. Therefore, deletion or duplication of the region can occur due to nonallelic homologous recombination events. Nearly $90 \%$ of patients with a deletion share a common $3-\mathrm{Mb}$ deletion, $8 \%$ have a smaller deletion $(1.5-\mathrm{Mb})$ and very rare cases have an even smaller one within the disease locus, called ,nested deletion”. The highly variable clinical presentation is not yet explained by the deletion size, therefore other undefined mechanisms must be involved $(3,4)$.

Most of the genes that lack in this disease have not been well characterized. Shorter deletions in the same region (contiguous gene deletion syndrome) appear in a small percentage of the affected individuals. However, the loss of a particular gene on chromosome $22, \underline{T B X 1}$, is probably responsible for most of the syndrome's characteristic signs (distinctive facial features, heart defects, hearing loss, low calcium levels and also behavioral problems). The increased risk of developing psychiatric and behavioral 
s

problems can also be explained by the loss of COMT gene, in the same region of chromosome 22 (5). However, some of the patients with classical features of the syndrome have smaller deletions that do not include TBX1, so the question remains as to whether other genes in the region contribute to the phenotype. Efforts to identify potential genetic modifiers of the cardiac phenotype are also underway $(6,7)$.

A person with a chromosome deletion has a $50 \%$ chance of transmitting the affection to their child (autosomal dominant transmission) (8). Yet, about $90 \%$ of the cases with a 22q11.2 deletion occur randomly during fertilization or fetal development, therefore, most of them are de novo (9).

\section{MANAGEMENT}

The most important step in managing a patient with a 22q11.2 deletion is to identify the exact phenotypic manifestations so that appropriate counseling and anticipatory care can be provided. Given the highly variable phenotype, the clinical evaluation will vary both in extent and by age. The International 22q11.2 Deletion Consortium provided guidelines on the management of the patients with VCFS (10).

\section{NEUROPSYCHIATRIC DISORDERS}

So far, it is not clear the biologic basis of mental illness in VCFS. However, the syndrome represents an excellent model for understanding psychiatric disorders, especially psychosis, in humans. Patients with VCFS have a 25 times higher rate of psychosis than general population. Therefore, it is almost certain that a genomic factor or factors in the deleted region influence brain development and/or function.

Childhood psychiatric manifestations of VCFS include mood dysregulation, anxiety disorders, attention deficit hyperactivity disorder (ADHD) and autism spectrum disorders (11). Attention deficit hyperactivity disorder (ADHD) was the most frequent disorder in children (37.10\%) and was overrepresented in males. Anxiety disorders were more prevalent than mood disorders at all ages, but especially in children and adolescents. In approximately $32 \%$ of individuals with VCFS, chronic psychosis presents between late adolescence and early adulthood, and most of these cases meet the criteria for schizophrenia. Anxiety and unipolar mood disorders were overrepresented in females. Psychotic disorders were present in $41 \%$ of adults over age 25. Males did not predominate in psychotic or autism spectrum disorders. Moreover, the adults show minimal resolution of psychiatric symptoms (12).

VCFS is the most commonly known genetic risk factor for schizophrenia. The $25 \%$ risk of developing schizophrenia is a great concern of the patients and their families given its gravity, social stigma and impact on functioning $(13,14,15,16)$. The schizophrenia associated with VCFS accounts for $0.5-1 \%$ of schizophrenia in the general population. There is no difference between this and other forms of schizophrenia regarding prodrome, age at onset, the core signs and symptoms, cognitive profile, except overall lower average IQ and the absence of gender differences $(17,18,19)$. Symptoms include delusions, hallucinations, disorganized thinking, emotional expression and/or behavior, as well as blunted affect, reduced speech, social withdrawal and motor disturbances $(20,21)$.

In the general population, psychiatric disorders such as anxiety disorders, schizophrenia and other psychotic disorders are effectively treated with both 
pros.

pharmacological and non-pharmacological therapies. For anxiety the latter can include cognitive behavioral therapy (CBT) and interpersonal psychotherapy (IPT). These recommendations are documented in the guidelines by the American Psychiatric Association (APA, United States of America) and the National Institute for Health and Care Excellence (NICE, United Kingdom). Clinicians may wonder if standard treatment strategies are feasible and effective in 22q11.2DS and if adaptations to treatment guidelines are required. For example, individuals with 22q11.2DS may need more time to establish a trusting relationship with clinicians, to process information, or may have difficulties understanding abstract information due to intellectual disabilities and deficits in socialization $(17,22)$.

Regarding the psychopharmacological treatment, the therapies need to be carefully chosen, taking into account literature data on tolerability and efficacy. Moreover, they seem to have a higher susceptibility to side effects than subjects with psychotic disorders (without VCFS). The antipsychotic medications have the potential to induce, exacerbate, or, interestingly, diminish preexisting movement disorders in some cases (23). Studies suggest an increased vulnerability to antipsychotic-related movement disorders in VCFS that may include drug-induced parkinsonism, dystonia and non-epileptic myoclonus (24, 25, 26). Other psychotropic medications commonly used in VCFS such as antidepressants and anticonvulsants can also cause adverse motor effects (27).

\section{SPEECH AND LANGUAGE IMPAIRMENT}

Studies report that 70 to $90 \%$ of the patients with VCFS present hypernasal speech, severe articulation impairment (28). Speech onset is usually mildly delayed and receptive language abilities exceed expressive. Some of them are related to unintelligible speech and incorrect management of these disorders in childhood (29). However, remediation of these problems has led to excellent prognosis in the large majority of cases.

\section{CONGENITAL HEART DISEASE}

Recent studies estimate that approximately $75-80 \%$ of patients with a $22 q 11.2$ deletion have congenital heart disease. These studies may overestimate the prevalence of cardiac defects in the deleted population given that children and adults without significant heart disease may escape diagnosis $(30,31)$.

The most common cardiac defects seen in the 22q11.2 deletion syndrome include a subset of conotruncal defects such as tetralogy of Fallot (26\%), interrupted aortic arch (10\%) or truncus arteriosus (10\%), pulmonary atresia with ventricular septal defect (24\%) and less commonly atrial septal defects $(30,32)$. The full range of aortic arch anomalies, including cervical aortic arch, double aortic arch, rightsided aortic arch and abnormal origin of the subclavian arteries (both aberrant and isolated subclavian arteries) have been observed (33). In addition to cardiovascular malformations, a subset of patients with the 22q11.2 deletion syndrome develops aortic root dilation over time, suggesting that this feature may be progressive. However, the clinical significance of this finding remains to be determined as there are no reports of aortic root dissection (34).

These diseases can be observed after a clinical examination to which are added paraclinical investigations: ECG, echocardiography, stress test, CT angiography, cardiac MRI. These cardiac diseases are compatible with life but require supervision and eventually surgical treatment. 


\section{CRANIOFACIAL DYSMORPHIA}

Patients with VCFS have a long face with a prominent upper jaw and an underdeveloped lower jaw, prominent nose with narrow nasal passages, long thin upper lip and a downslanting mouth. They also present flattening of the cheeks (4). However, the presence of these features as well as other facial findings is variable. Results from a prospective evaluation for ocular abnormalities in 33 patients with VCFS revealed hooding of the upper lids (41\%), ptosis (9\%), hooding of the lower lids (6\%), epicanthal folds (3\%) and distichiasis (abnormal growth of lashes from the orifices of the meibomian glands) (3\%). Strabismus was observed in $13 \%$ and amblyopia in $6 \%$ of the individuals $(3,6)$. The incidence of astigmatism, myopia and hyperopia was comparable to that in the general population. Ear abnormalities include overfolded or squared off helices, cupped, microtic and protuberant ears, also narrow external auditory meati.

\section{VELOPHARYNGEAL DYSFUNCTION}

Palatal anomalies are also common among children with VCFS, especially submucous cleft palate and occult submucous cleft palate (35). These clefts can be very difficult to identify without a nasopharyngoscopy. That is why several reports have significantly underestimated the frequency of clefting (36). It is for this reason that reports suggest that individuals with VCFS have "short palates" or hypernasal speech. More specifically, occult submucous cleft palate is an identifiable anomaly that is a form of cleft palate that often goes undetected because it requires endoscopic examination of the nasal surface of the velum (35). Stridor resulting from vascular ring, laryngomalacia and laryngeal web, laryngeal atresia and subglottic stenosis can also be found in these patients.

\section{IMMUNE DEFICIT}

Approximately $80 \%$ cases demonstrate some level of immunologic abnormality with most manifesting mild-to-moderate decrements in $\mathrm{T}$-cell numbers due to thymic hypoplasia and only a very rare minority $(0.5 \%)$ manifesting severe immunodeficiency that requires immediate medical attention. Patients may also experience humoral defects (26\%) and IgA deficiency (6\%) (37). In most of the cases, early childhood is marked by frequent respiratory infections, middle ear effusions and sinusitis. In the more severe cases, pneumonia and bronchitis may apear through childhood (28).

\section{HYPOCALCEMIA}

At least half of the infants with VCFS manifest hypocalcemia, which can result in hypocalcemic seizures if not recognized and treated appropriately. The hypocalcemia usually resolves by 1 year of age, but can reappear or present as isolated hypoparathyroidism for the first time at later ages (38).

\section{DIAGNOSIS}

The molecular diagnosis of a 22q11.2 deletion was previously made using fluorescence in situ hybridization of test probes from the 22q11.2 locus hybridized with metaphase chromosomes. While this approach reliably identified the typical 3-Mb deletion and some smaller deletions, it failed to detect the less common 'nested' or atypical deletions (3, 4, 39). Newer methods including MLPA and microarrays now identify both the common and atypical deletions in the region and are now the preferred methods of interrogation $(40,41)$.

\section{CLINICAL OUTCOME}

It is particularly important to know that features and symptoms, such as calcium homeostasis and neuropsychiatric issues, may 


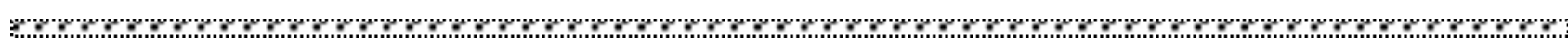
evolve over time and must be periodically reevaluated. Likewise, it is critical to screen parents for the 22q11.2 deletion in order to identify the previously undiagnosed adult as they have a $50 \%$ risk of recurrence in subsequent offspring and require clinical counseling to address their own clinical and neuropsychiatric needs.

Early reports revealed a high rate of mortality for patients with VCFS on account of inoperable cardiac malformations and severe infections. With medical and surgical advances, survival has significantly improved for all patients with congenital heart disease, but numerous studies suggest that cases with a malformation syndrome suffer worse clinical outcomes than those with apparently isolated congenital heart disease (31). To date, the management of the associated congenital heart malformations follows standard approaches, but as our understanding of the 22q11.2-deleted patients specific clinical challenges improve, care may soon be tailored to their specific needs (personalized, or genotype-specific, clinical management) (10, $31)$.

The multidisciplinary approach (geneticist, psychiatrist, cardiologist) is essential for the positive evolution of the patient with velocardiofacial syndrome. The patient requires periodic evaluation (at every 6 months) for monitoring and reassessment.

\section{ACKNOWLEDGEMENTS AND DISCLOSURES}

The authors declare that they have no potential conflicts of interest to disclose.

\section{REFERENCES}

1. Kobrynski LJ, Sullivan KE. Velocardiofacial syndrome, DiGeorge syndrome: the chromosome 22q11.2 deletion syndromes. Lancet. 2007; 370(9596):1443-1452.

2. Burnside, R. 22q11.21 Deletion Syndromes: A Review of Proximal, Central, and Distal Deletions and Their Associated Features. Cytogenetic and Genome Research, 2015; 146(2), 89-99.

3. Michaelovsky E, Frisch A, Carmel M et al. Genotype-phenotype correlation in 22q11.2 deletion syndrome. BMC Med Genet 2012; 13:122.

4. Verhagen JM, Diderich KE, Oudesluijs G et al. Phenotypic variability of atypical 22q11.2 deletions not including TBX1. Am J Med Genet A 2012; 158A:2412-2420.

5. Gao S, Li X, Amendt BA. Understanding the role of TBX1 as a candidate gene for 22q11.2 deletion syndrome. Curr Allergy Asthma Rep. 2013; 13(6):613-621.

6. Goldmuntz E, Driscoll DA, Emanuel BS et al. Evaluation of potential modifiers of the cardiac phenotype in the 22q11.2 deletion syndrome. Birth Defects Res A Clin Mol Teratol 2009; 85:125-129.

7. Guo T, McDonald-McGinn D, Blonska A et al. Genotype and cardiovascular phenotype correlations with TBX1 in 1,022 velo-cardio-facial/DiGeorge/22q11.2 deletion syndrome patients. Hum Mutat 2011; 32:1278- 1289.

8. Oskarsdottir S, Vujic M, Fasth A. Incidence and prevalence of the 22q11 deletion syndrome: a population-based study in Western Sweden. Arch Dis Child 2004; 89:148-151.

9. Cancrini C, Puliafito P, Digilio MC et al. Clinical features and follow-up in patients with $22 \mathrm{q} 11.2$ deletion syndrome. J Pediatr 2014; 164:1475-1480.

10. Bassett AS, McDonald-McGinn DM, Devriendt K et al. Practical guidelines for managing patients with $22 \mathrm{q} 11.2$ deletion syndrome. J Pediatr 2011; 159:332-339.

11. Feinstein C, Eliez S, Blasey C, Reiss AL. Psychiatric disorders and behavioral problems in children with velocardiofacial syndrome: usefulness as phenotypic indicators of schizophrenia risk. Biol Psychiatry. 2002; 51(4):3128 .

12. Gothelf D, Feinstein C, Thompson $\mathrm{T}$ el al. Risk factors for the emergence of psychotic disorders in adolescents with 22q11.2 deletion syndrome. Am J Psychiatry. 2007; 164(4):663-9.

13. Butcher NJ, Chow EW, Costain G et al. Functional outcomes of adults with $22 \mathrm{q} 11.2$ deletion syndrome. Genet Med. 2012;14(10):836-43. 
14. Hercher L, Bruenner G. Living with a child at risk for psychotic illness: the experience of parents coping with 22q11 deletion syndrome: an exploratory study. Am J Med Genet A. 2008;146A(18):2355-2360.

15. Karas DJ, Costain G, Chow EW, Bassett AS. Perceived burden and neuropsychiatric morbidities in adults with 22q11.2 deletion syndrome. J Intellect Disabil Res. 2014;58(2):198-210.

16. McDonald-McGinn DM, Sullivan KE, Marino B et al. 22q11.2 deletion syndrome. Nat Rev Dis Primers. 2015;1:15071.

17. Fung WL, Butcher NJ, Costain G et al. Practical guidelines for managing adults with 22q11.2 deletion syndrome. Genet Med. 2015;17(8):599-609.

18. Karayiorgou M, Simon TJ, Gogos JA. 22q11.2 microdeletions: linking DNA structural variation to brain dysfunction and schizophrenia. Nat Rev Neurosci. 2010;11(6):402-416.

19. van Amelsvoort T, Henry J, Morris R et al. Cognitive deficits associated with schizophrenia in velo-cardio-facial syndrome. Schizophr Res. 2004;70(2-3):223-232.

20. Tandon R, Gaebel W, Barch DM et al. Definition and description of schizophrenia in the DSM-5. Schizophr Res. 2013;150(1):3-10.

21. Walther S, Strik W. Motor symptoms and schizophrenia. Neuropsychobiology. 2012;66(2):77-92.

22. Buijs PCM, Bassett AS, Boot E. Non-pharmacological treatment of psychiatric disorders in individuals with 22q11.2 deletion syndrome; a systematic review. Am J Med Genet A. 2018;176(8):1742-1747.

23. Peluso MJ, Lewis SW, Barnes TR, Jones PB. Extrapyramidal motor side-effects of first- and second-generation antipsychotic drugs. Br J Psychiatry. 2012;200(5):387-392.

24. Boot E, Butcher NJ, van Amelsvoort TA et al. Movement disorders and other motor abnormalities in adults with 22q11.2 deletion syndrome. Am J Med Genet A. 2015;167A(3):639-645.

25. Butcher NJ, Marras C, Pondal M et al. Neuroimaging and clinical features in adults with a $22 \mathrm{q} 11.2$ deletion at risk of Parkinson's disease. Brain. 2017;140(5):1371-1383.

26. Kontoangelos K, Maillis A, Maltezou M et al. Acute Dystonia in a Patient with 22q11.2 Deletion Syndrome. Ment Illn. 2015;7(2):5902.

27. Kennedy GM, Lhatoo SD. CNS adverse events associated with antiepileptic drugs. CNS Drugs. 2008;22(9):739760 .

28. Shprintzen RJ. Velo-cardio-facial syndrome. In: Cassidy SB, Allanson J, editors. Management of Genetic Syndromes. 2. New York: Wiley-Liss; 2005b. pp. 615-632.

29. Golding-Kushner KJ. Therapy Techniques for Cleft Palate Speech and Related Disorders. San Diego: Singular Publishing Group; 2000.

30. Monteiro FP, Vieira TP, Sgardioli IC, et al. Defining new guidelines for screening the 22q11.2 deletion based on a clinical and dysmorphologic evaluation of 194 individuals and review of the literature. Eur J Pediatr. 2013; 172(7):927945.

31. Peyvandi S, Lupo PJ, Garbarini J et al. 22q11.2 deletions in patients with conotruncal defects: data from 1,610 consecutive cases. Pediatr Cardiol 2013; 34:1687-1694.

32. Momma K. Cardiovascular anomalies associated with chromosome 22q11.2 deletion syndrome. Am J Cardiol 2010; 105:1617- 1624 .

33. Fernández L, Nevado J, Santos F et al: A deletion and a duplication in distal 22q11.2 deletion syndrome region. Clinical implications and review. BMC Med Genet 2009; 10:48.

34. John AS, McDonald-McGinn DM, Zackai EH, Goldmuntz E. Aortic root dilation in patients with 22q11.2 deletion syndrome. Am J Med Genet A 2009; 149A:939-942.

35. Shprintzen RJ, Higgins AM, Antshel K et al. Velo-cardio-facial syndrome. Curr Opin Pediatr. 2005;17(6):725-730.

36. Oskarsdóttir S, Vujic M, Fasth A. Incidence and prevalence of the 22q11 deletion syndrome: a population-based study in Western Sweden. Arch Dis Child. 2004;89(2):148-151.

37. Agergaard P, Olesen C, Ostergaard JR et al. The prevalence of chromosome 22q11.2 deletions in 2,478 children with cardiovascular malformations. A population-based study. Am J Med Genet A 2012; 158A:498-508.

38. Habel A, Herriot R, Kumararatne D et al. Towards a safety net for management of 22q11.2 deletion syndrome: guidelines for our times. Eur J Pediatr. 2014;173(6):757-765.

39. Portnoi MF. Microduplication 22q11.2: a new chromosomal syndrome. Eur J Med Genet 2009; $52: 88$-93.

40. Ziolkowska L, Kawalec W, Turska-Kmiec A et al. Chromosome 22q11.2 microdeletion in children with conotruncal heart defects: frequency, associated cardiovascular anomalies, and outcome following cardiac surgery. Eur J Pediatr 2008;167:1135-1140. 
62/Bulletin of Integrative Psychiatry ONew Series O December 2019 ○ Year XXV ○ No. 4 (83)

(1) 41. O'Byrne ML, Yang W, Mercer-Rosa L et al. 22q11.2 deletion syndrome is associated with increased perioperative events and more complicated postoperative course in infants undergoing infant operative correction of truncus arteriosus communis or interrupted aortic arch. J Thorac Cardiovasc Surg 2014; 148:1597-1605.

\section{Correspondence:}

Maria-Magdalena Leon-Constantin,

Universitatea de Medicină și Farmacie "Grigore T Popa" - Iasi, Romania, Facultatea de Medicină, Departamentul Medicale I, Strada Universității nr 16, Iasi, Romania; Spitalul Clinic de Recuperare - Clinica de Recuperare Cardiovasculară, adresa: Str Pantelimon Halipa nr 14, Iasi, Romania e-mail: leon_mariamagdalena@yahoo.com 